\title{
FUNCTIONAL PLASMA-DEPOSITED COATINGS
}

\author{
Mykhaylo Pashechko', Myroslav Kindrachuk' ${ }^{2}$ Igor Gumeniuk ${ }^{2}$, \\ Oleksandr Tisov ${ }^{2}$, Volodymyr Zahrebelniy ${ }^{2}$ \\ 1 Department of Fundamentals of Technology, Lublin University of Technology, Nadbystrzycka 38, 20-618 \\ Lublin, Poland, e-mail: mpashechko@hotmail.com \\ 2 Engineering Department, National Aviation University, Kyiv, Ukraine
}

Received: 2017.06.25 Accepted: 2017.11.02 Published: 2017.12 .05

\begin{abstract}
The paper focuses on the problem of low adhesion of plasma sprayed coatings to the substrate. The subsequent laser treatment modes and their influence on the coatingsubstrate interface were studied. This allows to decrease the level of met-stability of the coating, thus decreasing its hardness down to 11-12 GPa on the surface and to about $9 \mathrm{GPa}$ on depth of $400 \mu \mathrm{m}$. The redistribution of alloying elements through solid and liquid diffusion improves mechanical properties and rises the adhesion up to $450 \mathrm{MPa}$ after remelting and up to $90-110 \mathrm{MPa}$ after laser-aided thermal cycling. At the same time, remelting of coating helps to decrease its porosity down to $1 \%$. The obtained complex of properties also allows to improve wear resistance of coatings and to decrease friction factor.
\end{abstract}

Keywords: plasma deposition, coating, laser treatment, thermal cycling, mass transfer, adhesion, wear resistance.

\section{INTRODUCTION}

In contemporary manufacturing processes of machine elements the technologies of depositing functional coatings are widely used. This allows to increase the service life of parts, and to cut manufacturing and service expenses. Among the most common are the coatings deposited by plasma spraying or gas arc welding of powder materials $[3,9,11,14]$.

A well-known disadvantage of these coatings - is their poor adhesion, which is about $2-3 \mathrm{MPa}$ and is very seldom stronger $[5,10,13]$. They also cannot be used at cyclic loading conditions because of the risk of spallation. Their porosity makes them impossible to be used in pressurized gases or oils and at high temperatures,

A well-known fact is that the mechanical properties of material surface layer can be advanced by laser treatment $[2,6]$. Both in liquid and solid phases the alloying elements under laser radiation and other thermal influences are redistributed [12]. The rate of redistribution is extremely high, what cannot be achieved by conventional heating [1, 4, 8]. This phenomenon, if utilized on coating, may improve the coating adhesion. To investigate the mode of laser heating, which will provide such redistribution - is the aim of current paper.

This paper is focused on general relations of mass transfer in the plasma coating-substrate interface under the laser treatment what will provide better adhesion and higher wear resistance.

\section{MATERIALS AND METHODS}

Material for plasma coating - are alloy steels VTN $\left(\mathrm{TiB}_{2}-\mathrm{VC}+0.12 \mathrm{C}-18 \mathrm{Cr}-10 \mathrm{Ni}-\mathrm{Ti}\right)$ and $\mathrm{CrTN}\left(\mathrm{TiB}_{2}-\mathrm{CrB}_{2}+0.12 \mathrm{C}-18 \mathrm{Cr}-10 \mathrm{Ni}-\mathrm{Ti}\right)$. As substrate material we used austenitic steel $0.12 \mathrm{C}-18 \mathrm{Cr}-10 \mathrm{Ni}-\mathrm{Ti}$.

The surface laser treatment was done by $\mathrm{CO}_{2}$ laser. Radiation power $\mathrm{P}=1000 \mathrm{~W}$, ray diameter $d=2.5-10 \mathrm{~mm}$. The speed of ray motion $v=0.5$ $\mathrm{m} / \mathrm{min}$. Pitch of treatment $S=1,5-5 \mathrm{~mm}$. This allows to heat or remelt the coating to the required 
depth. The specimens were analyzed for structural arrangement, hardness distribution. The distribution of chemical elements was studied by microanalyzer REMMA-106И. The adhesion was determined by pull-off adhesion test. After spray deposition coatings were treated by laser thermal cycling (periodic heating-self cooling).

For wear testing a ring-on-ring method was used. Relative sliding speed of movable specimen was up to $15 \mathrm{~m} / \mathrm{sec}$. Test temperature range from room - up to $1000{ }^{\circ} \mathrm{C}$. Contact load range 1-7 MPa.

\section{RESULTS AND DISCUSSION}

The microstructure of remelted coating. has dendritic structure. Under high solidification rate the dendrites are directed to the side of heat removal. At the top surface the solidification rate was extremely high, as there are no dendrites. The structure is fine-dispersed. It was obtained by double remelting of plasma coating with higher speed of ray motion (more than $1 \mathrm{~m} / \mathrm{min}$ ). The hardness of this surface layer is $11000-12000 \mathrm{MPa}$ and its hardness is lower comparing to initial plasma coating with no subsequent treatment (Fig. 1). Hardness gradually decreases from top to the interface in remelted coating, and hardness drop is more significant and rapid for untreated coating.

Microhardness of substrate material is unchanged and is about $2700 \mathrm{MPa}$. The coating

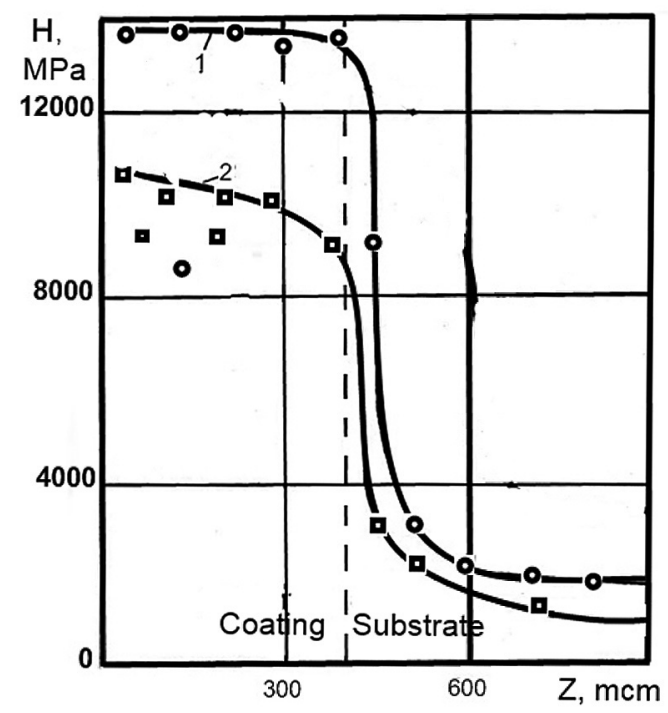

Fig. 1. Hardness gradient of plasma-sprayed coatings from top to depth: as-deposited (1), remelted (2). Substrate steel $0.12 \mathrm{C}-18 \mathrm{Cr}-10 \mathrm{Ni}-\mathrm{Ti}$ after remelting becomes almost fully solid with porosity only about $0.5-1.0 \%$, the adhesion rises up to $400-450 \mathrm{MPa}$.

A great attention was paid to the distribution of alloying elements in the interface zone. Metallographic analyses of remelted coating on steel $0.12 \mathrm{C}-18 \mathrm{Cr}-10 \mathrm{Ni}-\mathrm{Ti}$ substrate indicates the absence of cracks and spallation, and a distinct boundary «substrate-coating» A «grey zone» (upper layer of substrate) was discovered. Its thickness is about $1.5-2 \mu \mathrm{m}$, and its chemical composition differs from those of coating and substrate - the content of vanadium, chromium and manganese is increased. We may state, that matrix and substrate materials diffuse into each other. Iron from substrate interacts with vanadium and chromium and diffuses into coating. It is necessary to point on high titanium content in coating material (Fig. 2). These data show that rapid heating by laser causes in the coating-substrate interface a mass transfer and formation of transition zone. This provides much higher adhesion and positive gradient of hardness.

To determine positive influence of laser treatment (without remelting) special investigation was carried out. The VTN and CrTN alloys were plasma sprayed to the surface of $0.12 \mathrm{C}$ 18Cr-10Ni-Ti austenitic steel. They were laser treated in thermocycling mode (laser rapid heating + self-cooling). The temperature range was $1000 \leftrightarrow 600{ }^{\circ} \mathrm{C}$, what encloses the polymorphic transformation range.

The three times of cycling causes noticeable decrease of hardness and brittleness. The grey transition zone expands.

After 4 times treatment hardness of eutectic zone decreases from $9750 \mathrm{MPa}$ to $8740 \mathrm{MPa}$. White metstable layers on the top of the coating also became softer: de- crease from 13400 down to $9100 \mathrm{MPa}$.

Increasing the number of treatments up to 5 times, excessive brittleness is removed completely. The separation of insoluble particles from solid solution is observed.

After 6 thermocycles the hardness of upper and internal layers of coating are almost identical. It is lower than the hardness of as-deposited coating, but is higher than the hardness of a remelted coating. Further increase of thermocycles do not give any positive results. It is seen from Table 1. The 4-times cycling has the best influence on material's properties and adhesion.

Wear test (Fig. 3) indicates decrease of wearing for 4-times remelted coating and lower fric- 
a)

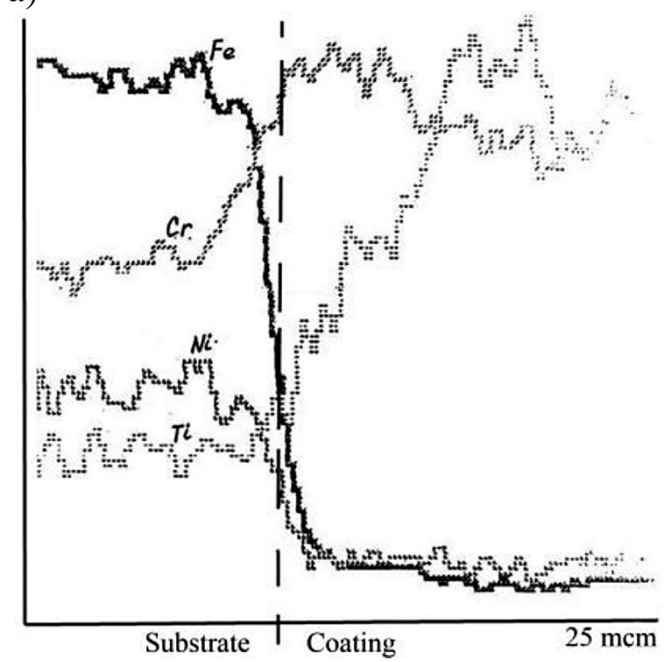

b)

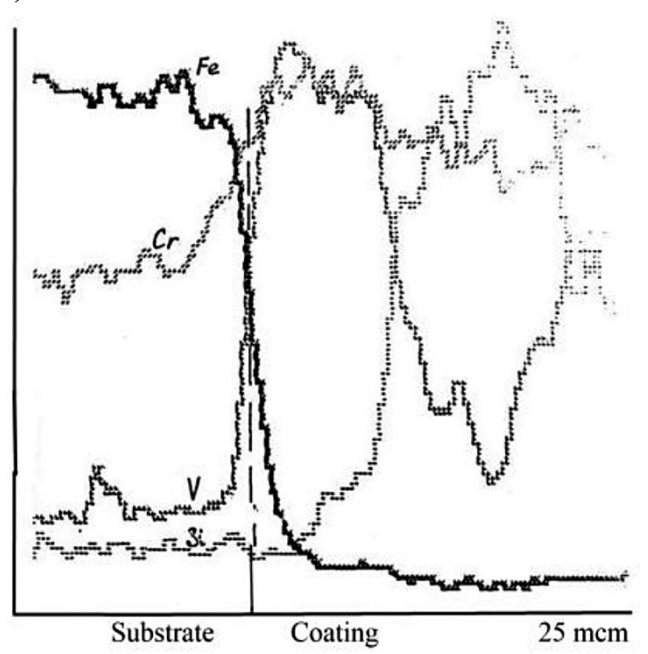

Fig. 2. Distribution of chemical elements in the interface of remelted plasma-sprayed VTN coating (a) and $0.12 \mathrm{C}-18 \mathrm{Cr}-10 \mathrm{Ni}-\mathrm{Ti}$ steel substrate (b)

Table 1. Properties of the coatings

\begin{tabular}{|l|c|c|c|}
\hline \multicolumn{1}{|c|}{ Condition of the coating } & Micro-hardness [MPa] & Porosity [\%] & Adhesion [MPa] \\
\hline Plasma coating & 12400 & $10-12$ & $16-20$ \\
\hline Laser melting & 8200 & $0.5-1.0$ & $400-450$ \\
\hline Laser thermo-cycled plasma coating (4 cycles) & 10050 & $7-9$ & $90-110$ \\
\hline
\end{tabular}

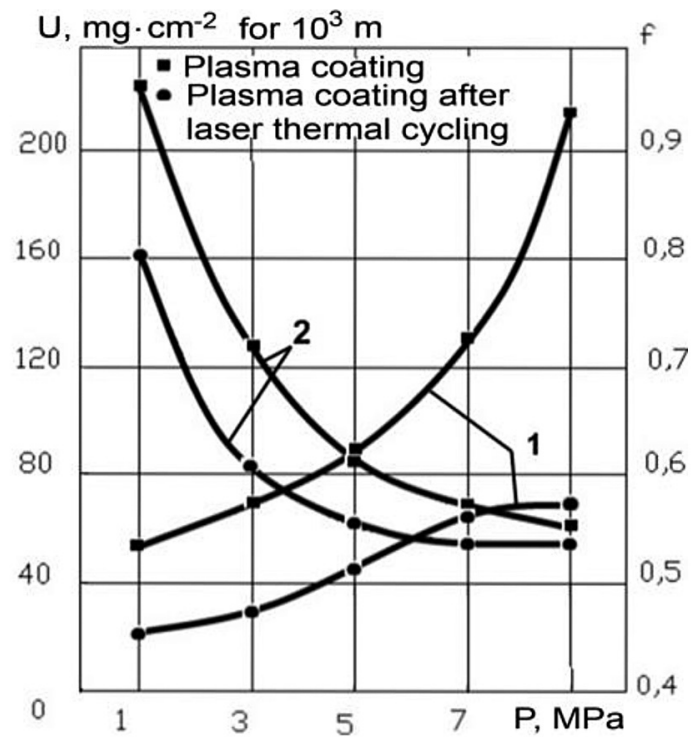

Fig. 3. Wear test results for VTN-coating: 1 - wearing, 2 - friction factor

tion factor. The friction process is also more stable comparing to as-deposited coating. Friction factor decreases in almost three times, what may be explained by the loss of mechanical strength due to friction-induced heat and cold metal flow under load. But in this case the wear intensity also would be very high. In contrast, it is slightly changed while 7-times increase of load. This is explained by formation of wear resistant protective layer on the surface of wear track [7].

Decrease of brittleness and increase of plasticity promotes the formation of stable friction induced surface structures, and thus increases wear resistance. Also these structures cover the entire surface, in contrast to the wear surface of as-deposited plasma-sprayed coatings, which have only partially formed friction induced structure.

\section{CONCLUSION}

If the coating is laser-melted, the liquid phase interaction with substrate results in intensive mass transfer and formation of very strong interface. The adhesion is raised to $400-450 \mathrm{MPa}$ and porosity is below $1 \%$. Laser thermocycling causes valuable redistribution of alloying elements in the coating-substrate interface. The thermocycling in a range of polymorphic transformation temperatures leads to increase of adhesion in 4-5 times (up to 90-110 MPa), removes excessive hardness and brittleness. This also promotes the formation of stable full-area friction induced surface layer, what results in low wearing and friction factor. 


\section{REFERENCES}

1. Borovsky`j Y.B., Gorodsky`j D.Zh., Sharafeev Y.N., Moryashhev S.F. Vass transfer at surface treatment of metals by melting using pulse laser irradiation. Reports AN SSSR. Vol. 263, 1982, 616687 (In Russian).

2. Castañeda E., Rubio-Gonzalez C., Chavez-Chavez A., Gomez-Rosas G. Laser shock processing with different conditions of treatment on duplex stainless steel. Journal of Materials Engineering and Performance, 24(6), 2015, 2521-2525.

3. Fauchais P.L., Heberlein J.V.R., Boulos M.I. Industrial applications of thermal spraying technology. In book: Thermal Spray Fundamentals, 2013, pp. 1401-1566.

4. Gerczry`ken D.S., Mazanko V.F., Fal’ chenko V.M. Pulse treatment and mass transfer in metals at low temperatures. Nauk. dumka, 1991, pp. 208 (In Russian).

5. Khatri S., Smith R., Jokiel P., Lugscheider E., Bohley M. Plasma spraying of high-nitrogen-bearing steels for wear-resistant coatings and structural applications. Journal of Materials Engineering and Performance, 3(4), 1994, 476-483.

6. Kindrachuk M.V. The influence of eutectic plasma coating's structure on their tribotechnical properties in a wide temperature range. FizikoKhimicheskaya Mekhanika Materialov, 30(4), 1994, 66-71.
7. Kindrachuk M.V., Dushek Yu.Ya., Luchka M.V., Gladchenko A.N. Evolution of the structure and properties of eutectic coatings during friction. Powder Metallurgy and Metal Ceramics, 34(5), 1995, 321-326.

8. Kovalenko V.S., Verxoturov A.D., Golovko L.F., Podchernyaeva Y.A. Laser and electroerrosion strengthening of materials. Nauka, 1986, pp. 276. (In Russian).

9. Kuzneczov V.D. , Pashhenko V.M. Phisical and chemical fundamentals of coatins formation. NMCz VO, 1999, pp. 176 (In Ukrainian).

10. Pashechko M. Golubets V., Stefanishin I. Hot gas eutectic coatings made of powder materials of the Fe-Mn-C-B system. Soviet Materials Science, 25(3), 1989, 270-272.

11. Pashechko M. Wear resistance of eutectic coatings of the Fe-Mn-C-B system alloyed with $\mathrm{Si}, \mathrm{Ni}$ and Cr. Materials Science, 46(5), 2011, 695-701.

12. Paustovskii A.V., Botvinko V.P. Phase composition of the surface layers of high-speed cutting steel after electrospark alloying and laser treatment. Materials Science, 36(1), 2000, 100-103.

13. Syed A.A., Denoirjean A., Denoirjean P., Labbe J.C., Fauchais P. In-flight oxidation of stainless steel particles in plasma spraying. Journal of Thermal Spray Technology, 14(1), 2005, 117-124.

14. Yushhenko K.A., Borysov Yu.S., Kuzneczov V.D., Korzh V.M. Surface engineering. Naukova dumka, 2007, pp. 559 (In Ukrainian). 